\title{
Storytelling to Inspire Dialysis Patients to Learn about Living Donor Kidney Transplant
}

\author{
Emily H. Wood ${ }^{a}$ Amy D. Waterman ${ }^{a, b}$ Rachyl Pines ${ }^{c}$ \\ aDavid Geffen School of Medicine, Los Angeles, CA, USA; ${ }^{\text {T} T e r a s a k i ~ I n s t i t u t e ~ f o r ~ B i o m e d i c a l ~ I n n o v a t i o n, ~ L o s ~ A n g e l e s, ~}$ \\ CA, USA; 'Cottage Hospital, Santa Barbara, CA, USA
}

\section{Keywords \\ Dialysis · Kidney transplant - Transplant education · Living donor - Storytelling - Barriers - Waitlisting - Wait-listing · \\ Digital storytelling $\cdot$ Best practice recommendations}

\begin{abstract}
Background: Policy changes including the Advancing American Kidney Health initiative and CMS's ESRD Quality Incentive Program recommend increasing educational initiatives within dialysis centers to increase living kidney donor transplant (LDKT) rates. LDKT education can be challenging in dialysis centers due to limited provider time to educate, patient fears or reluctance to learn about LDKT, and difficulty educating potential living donors. New educational innovations that increase dialysis patient curiosity about pursuing LDKT are needed. Summary: Digital first-person storytelling, or the sharing of narratives by individuals in their own words, is a culturally competent, health literate, patient-driven approach to expanding patient understanding about LDKT that can supplement traditional educational strategies without additional burden for dialysis providers. The Living Donation Storytelling Project is an online digital library of over 150 video stories told by diverse kidney recipients, donors, those in search of a donor, and their family/friends. By hon-
\end{abstract}

estly discussing how they overcame fears and challenges related to LDKT, these stories address sensitive topics that can be hard for providers to introduce by using easily accessible learning methodology that may better connect with racial/ ethnic minorities, scared patients, and patients facing health literacy challenges. Key Messages: Supplementing traditional educational approaches with digital storytelling may help overcome time limitations in educating for busy providers, boost providers' own knowledge about LDKT, serve as a free supplemental resource for patients, reduce fears and increase self-efficacy about transplant, help more patients to share about transplant with their social networks, and ultimately increase LDKT rates.

(c) 2021 S. Karger AG, Basel

\section{Background}

Recent policy changes have been introduced to incentivize dialysis centers to increase the number of their patients being referred for transplant evaluation and becoming waitlisted. Starting in 2020, under the ESRD Quality Incentive Program (QIP), the Centers for Medicare and Medicaid Services (CMS) mandate that centers report their Percentage of Prevalent Patients Waitlisted

$\begin{aligned} & \text { karger@karger.com } \\ & \text { www.karger.com/bpu }\end{aligned}$
Karger ${ }^{\prime /}$


(PPPW) on the kidney or kidney-pancreas transplant waitlist. Centers not showing sufficient PPPW may see payment reductions up to $2 \%$ in 2022 and subsequent years $[1,2]$. In addition, the new Advancing American Kidney Health executive order seeks to reduce the number of Americans developing ESKD by $25 \%$ by 2030 , to double the number of kidney transplants available, and shift payment models to support home dialysis and kidney transplant for most new ESKD patients by 2025 [3].

Through transplant, ESKD patients can improve their quality and length of life significantly. After 5 years on dialysis, only $45 \%$ of patients are still alive, compared to $82 \%$ of deceased donor kidney transplant (DDKT) recipients and $92 \%$ of living donor kidney transplant (LDKT) recipients [4]. With these new policies linking dialysis funding to transplant referrals, dialysis centers need to continue improving their ability to educate and refer more patients for transplant, particularly black and Latinx patients who are still less likely to receive DDKTs or LDKTs than whites [5]. Past research has identified many provider barriers to effectively delivering education about transplant such as time limitations and poor access to materials [6-8] and patient barriers to learning such as fears, low health literacy, and medical mistrust [9-14].

It may be time to consider utilizing new educational innovations that decrease providers' educational burden and increase patient curiosity about pursuing LDKT. Digital first-person storytelling (FPS), or the sharing of narratives by individuals in their own words through digital technology, is a culturally competent, health literate, patient-driven approach to expanding patient understanding about LDKT that can supplement traditional educational strategies. FPS has been shown to increase patient knowledge, change attitudes and behavior, and improve clinical outcomes (e.g., A1C) when combined with traditional education [15]. This review will summarize 5 barriers to education about LDKT within the dialysis setting, introduce the utility of a digital storytelling library of stories called the Living Donation Storytelling Project, and provide recommendations for utilizing digital storytelling to overcome these barriers, particularly for patients known to be less interested in LDKT.

\section{Educational Barriers to Transplant in Dialysis Centers}

Previous research has found 5 common barriers to delivering LDKT education to dialysis patients and to increasing patient curiosity and learning about it. These barriers are (1) limited provider knowledge and comfort educating about transplant and LDKT [6, 7], (2) limited time to educate about transplant and LDKT $[6-8,16],(3)$ insufficient educational resources for patients with low health literacy [9-11], diverse patients [14, 17, 18], and those less ready to pursue transplant [19], (4) high rates of patient fears and misconceptions about transplant and LDKT $[12,14,18]$, and (5) difficulty reaching family, friends, or potential living donors to learn about transplant and LDKT $[7,20]$.

\section{Limited Provider Knowledge and Comfort Educating about Transplant and LDKT}

Research has shown that dialysis providers have gaps in their transplant-related training and knowledge. Previous work by Waterman et al. [7] found that dialysis administrators were only able to answer transplant knowledge questions correctly $50 \%$ of the time, reported that their staff were not trained to educate about transplantation, and over $90 \%$ agreed that dialysis providers needed better access to education resources. A 2017 survey of dialysis providers found that approximately one-third reported not being sufficiently knowledgeable about transplant to address most patient questions and somewhat or strongly disagreed that they felt confident as transplant educators [6].

\section{Limited Time to Educate about Transplant and LDKT}

Dialysis providers must educate patients about the complex process and risks and benefits of transplant along with managing their other clinical responsibilities. Many report having limited time available to educate about transplant [6-8] and sometimes report perceiving a lack of leadership support for this priority $[7,8,16]$. Balhara et al. [8] found that over $80 \%$ of providers reported spending $<20 \mathrm{~min}$ on transplant education, despite believing that more time was necessary. Similarly, McSorley et al. [6] found that half of the providers in their survey reported having insufficient time for transplant education and over $60 \%$ reported insufficient time to educate patient's family or friends about living donation.

\section{Insufficient Educational Resources for Some Patient Populations}

Previous research has demonstrated the prevalence of low health literacy among patients with CKD and ESRD, which is associated with lower likelihood to pursue transplant, especially LDKT [9-11], and the need for culturally tailored materials for use with African American and Latinx populations $[14,17,18]$. While interventions us- 
ing health literate, culturally sensitive educational resources in print, $\mathrm{Web}$, or video formats have been shown to be effective with minority groups $[21,22]$ and patients who are earlier in their readiness to pursue transplant and LDKT $[19,23]$, this type of tailored information written for low health literacy audiences is not always available.

\section{High Rates of Patient Fears and Misconceptions about} Transplant and LDKT

Many patients have higher rates of medical mistrust and perceived discrimination [12-14] (e.g., belief that the organ allocation system is unfair), cultural and religious beliefs that may not align with transplant/donation [13, 24-27], misconceptions about transplant and living donation (e.g., belief that the recipient takes on personality traits of the donor or belief that being a donor shortens life expectancy) $[12,14]$, and fears about the surgery, organ rejection, and death, or harming a living donor (e.g., fear that a donor would later develop ESKD) [12, 18]. Traditional education may not use approaches shown to be most effective for early learners, including gradual introduction of topics, and progressive calls to action, as recommended by the Transtheoretical Model of Behavioral Change [19]. Previous work by Waterman et al. [19] has shown that tailoring education to include all levels of readiness for patients is more effective at increasing knowledge and protransplant actions for these groups.

\section{Difficulty Reaching Potential Living Donors to Learn about Transplant and LDKT}

Generally, patients attend dialysis alone and dialysis providers have few opportunities to educate family or caregivers about transplant and living donation [7]. Many patients report reluctance to discuss living donation with family or close friends for fear of being rejected, harming a loved one, creating a sense of obligation, or out of discomfort accepting from a loved one $[28,29]$. As a result, dialysis patients may not share about transplant with those in their social networks who could provide support or be donors [6]. Sheu et al. [14] found that when possible, family members played a supportive role for deciding about renal replacement options, including transplant, and recommended placing greater emphasis on involving family in the education and decision-making process. Interventions that include family members have been shown to be more successful at increasing LDKT rates [20].
Research Update: Utility of Digital Storytelling for

\section{Health Education}

Stories are a universal pattern of communication that helps us connect with and recall information [15]. Digital FPS, or the sharing of narratives by individuals in their own words through digital content such as videos or animations, is a culturally competent, health literate, patientdriven, easy-to-deliver approach to learning about LDKT that adds little burden for the provider. In 2 previous works, we have investigated the potential of using storytelling within education to improve knowledge and health behaviors, particularly for transplant. A scoping review of 12 randomized controlled trials (RCTs) and 10 nonRCTs found that attitudes, knowledge, behaviors, and clinical outcomes for health conditions including cancer, diabetes, and hypertension improved when FPS was included [15]. Notably, all RCTs showed a greater increase in knowledge for the FPS condition compared to standard of care education. The majority of RCTs demonstrated a desired change in health-related behaviors (e.g., quitting smoking and getting vaccinated) and specific clinical outcomes (e.g., A1C level and blood pressure) compared to the control condition. In addition, for those studies that looked at FPS and its impact for hard to reach communities - racial/ethnic minorities, low income, or high school education only - FPS was shown to have a positive impact on attitudes, knowledge, behavior, and clinical outcomes, both in RCT (compared to standard education) and non-RCT interventions (compared to baseline).

Recognizing the potential of storytelling for transplant education, we designed and built a digital storytelling library of LDKT stories from a diverse set of real living donors, recipients, and their family and friends [30]. Over $80 \%$ reported that they were motivated by a desire to educate the public about living donation, show people how living donation can make a difference for both the recipient and donor, and help others looking for more information about living donation.

An innovative digital platform with open-ended guided prompts allowed storytellers to record a video from any smartphone, laptop, or tablet with a camera. The technology then spliced together all prompts into one cohesive video that underwent ethical review and editing to remove any protected health information disclosures, medical inaccuracies, or pressuring statements. Final videos were added to a searchable digital library and could also be shared via email or social media, especially for those who were seeking a living donor kidney. Future work involves expanding the library to include stories in 
Table 1. Content topics covered by different types of storytellers available within the Living Donation Storytelling Library

\begin{tabular}{|c|c|c|c|}
\hline $\begin{array}{l}\text { - Reasons recipient decided to get a } \\
\text { transplant and LDKT specifically } \\
\text { - Challenges of life on dialysis } \\
\text { - How recipients shared their need } \\
\text { for a transplant with others and } \\
\text { how they found a living donor } \\
\text { - Advice for other recipients, what } \\
\text { they wish they had known at the } \\
\text { start } \\
\text { - Myth-busting common } \\
\text { misconceptions (e.g., donors } \\
\text { cannot get pregnant later and } \\
\text { donors have a shorter life } \\
\text { expectancy) } \\
\text { - The most surprising thing they } \\
\text { learned about LDKT } \\
\text { - Accepting a kidney from a child } \\
\text { or family member } \\
\text { - The option of KPD and why do it } \\
\text { - The recovery process and what it } \\
\text { feels like living with a new kidney } \\
\text { - Best moments after surgery } \\
\text { - Renewed freedom after transplant } \\
\text { - Ways that transplant changed } \\
\text { their life or relationships } \\
\text { - Daily living with a transplant - } \\
\text { medications, routine clinic visits } \\
\text { etc. } \\
\text { - Emotions they experienced across } \\
\text { stages of the process } \\
\text { - Information they looked for, and } \\
\text { what sources it came from }\end{array}$ & $\begin{array}{l}\text { - Advice for other donors } \\
\text { - Myth-busting common misconceptions } \\
\text { (e.g., donors cannot get pregnant later and } \\
\text { donors have a shorter life expectancy) } \\
\text { - Motivations to donate including spiritual } \\
\text { reasons } \\
\text { - Making the decision to donate } \\
\text { - Why some donors donate to a stranger } \\
\text { - The option of KPD and why do it } \\
\text { - The most surprising thing they learned } \\
\text { about LDKT } \\
\text { - Predonation fears and how donors } \\
\text { overcame them } \\
\text { - Telling friends and family that about their } \\
\text { decision to be a donor } \\
\text { - How donors dealt with family and friends' } \\
\text { positive and negative reactions to their } \\
\text { decision to donate } \\
\text { - What kind of support they did or did not } \\
\text { receive through the donation process } \\
\text { - Ways that the Living Donor Advocate } \\
\text { confidentially supported them during the } \\
\text { process } \\
\text { - Dietary restrictions postdonation } \\
\text { - The recovery process and how long it } \\
\text { takes to feel back to normal after donation } \\
\text { - Best moments after surgery } \\
\text { - Health and life after donation } \\
\text { - What they wished they knew at the start } \\
\text { - Feelings about having become a donor } \\
\text { - Emotions they experienced across stages } \\
\text { of the process } \\
\text { - Information they looked for, and what } \\
\text { sources it came from }\end{array}$ & $\begin{array}{l}\text { - Who is affected by kidney } \\
\text { failure } \\
\text { - Why they hope to get a } \\
\text { transplant } \\
\text { - Advantages of transplant over } \\
\text { dialysis } \\
\text { - Making the choice to pursue } \\
\text { LDKT } \\
\text { - How to spread the word about } \\
\text { their desire for a transplant } \\
\text { - Asking someone to be their } \\
\text { donor } \\
\text { - How friends and family can } \\
\text { help as a kidney champion } \\
\text { - The option of KPD in the } \\
\text { event that a willing donor is } \\
\text { not a match } \\
\text { - How kidney patients keep } \\
\text { their spirits up and maintain } \\
\text { hope } \\
\text { - Ways that receiving a } \\
\text { transplant would change their } \\
\text { life } \\
\text { - Ways to help share their story } \\
\text { - Ways to get in touch if a } \\
\text { viewer would consider } \\
\text { becoming a donor } \\
\text { - Emotions they experience } \\
\text { while waiting for a transplant }\end{array}$ & $\begin{array}{l}\text { - Advice they give to others } \\
\text { - Challenges of living with or } \\
\text { caring for someone on } \\
\text { dialysis } \\
\text { - Common questions and } \\
\text { concerns family and friends } \\
\text { had when first hearing } \\
\text { about LDKT } \\
\text { - Information they looked } \\
\text { for, and what sources it } \\
\text { came from } \\
\text { - Ways to help out during the } \\
\text { transplant evaluation, } \\
\text { surgery, and recovery } \\
\text { process } \\
\text { - Best moments after a loved } \\
\text { one underwent transplant } \\
\text { or donation }\end{array}$ \\
\hline
\end{tabular}

KPD, kidney paired donation; LDKT, living kidney donor transplant.

other languages. The Living Donation Storytelling Project is available at www.explorelivingdonation.org for use by any patient, donor, or healthcare practitioner; see Table 1 for included topics.

\section{Key Messages: Best Practice Recommendations for Using Storytelling with Dialysis Patients}

To successfully increase waitlisting rates, dialysis centers must leverage new educational techniques that are better suited to overcome the 5 key barriers described above. Research has shown that dialysis centers using multiple educational practices are more successful at increasing the number of patients on the waitlist [23]. Table 2 outlines key recommendations for overcoming educational barriers in dialysis centers using digital storytelling.
Recommendation 1: Use Compilation Videos

Addressing Special Topics to Support Providers with

Less Transplant Expertise or Comfort Educating

Mini compilation videos covering key topics can be shared with patients during educational sessions, helping to cover sensitive or more complex topics. For example, we created videos on topics including "What is the transplant evaluation like?" "Accepting a kidney from your child or a relative," and "What is kidney paired exchange?"

\section{Recommendation 2: Use Video Stories as a}

Supplementary Resource to Support Busy Providers

Video stories can be used at many timepoints including while educating chairside, as a reinforcement delivered as a follow-up to oral transplant education, as a resource sent home with patients for access anytime, or delivered to patients electronically through email newsletters, dialysis 
Table 2. Recommendations for overcoming educational barriers in dialysis centers using digital storytelling

\begin{tabular}{|c|c|}
\hline Barrier & Digital storytelling solution \\
\hline $\begin{array}{l}\text { Limited provider knowledge and comfort } \\
\text { educating about transplant and LDKT }\end{array}$ & $\begin{array}{l}\text { Exploration of the library personally to learn more about common transplant and living donor experiences } \\
\text { from both patients and living donors } \\
\text { Review of how patients and donors directly address hard-to-field topics when preparing clinical answers } \\
\text { Show a living donation compilation video when provider is less experienced on a topic }\end{array}$ \\
\hline $\begin{array}{l}\text { Limited time to educate about transplant } \\
\text { and LDKT }\end{array}$ & $\begin{array}{l}\text { Build education - and video stories - into the care delivery plan the same way along with traditional educationa } \\
\text { methodologies } \\
\text { Allow patients to explore areas of the library based on their own interests on topic and preference for storyteller } \\
\text { Use mini topic videos as light refreshers quarterly, including "What would I tell another patient about } \\
\text { transplant?" and "How did my life change after transplant?" } \\
\text { Use videos in situations where support groups or mentoring programs may not be available due to time } \\
\text { constraints, geographic barriers, and COVID-19 challenges }\end{array}$ \\
\hline $\begin{array}{l}\text { Insufficient educational resources for } \\
\text { different low health literacy and diverse } \\
\text { patient populations and those less ready } \\
\text { to learn about LDKT }\end{array}$ & $\begin{array}{l}\text { Use patient and donor stories as a gentle entry into learning for patients have difficulty reading or } \\
\text { understanding complex transplant topics } \\
\text { Choose stories of } 1-5 \text { min. This type of chunked learning makes it easier for patients to process and recall } \\
\text { information without becoming overwhelmed } \\
\text { Let patients watch storytellers who are of the same race/ethnicity as them or share similar concerns }\end{array}$ \\
\hline $\begin{array}{l}\text { High rates of patient fears and } \\
\text { misconceptions about transplant and } \\
\text { LDKT }\end{array}$ & $\begin{array}{l}\text { Use video stories to address known areas of fear including, "How can I find a donor?" and "How could I allow } \\
\text { my child to be a donor for me?" } \\
\text { Show resources with memorable emotional valence (e.g., funny, moving, and positive) to help ease patients' } \\
\text { fears about learning more about transplant } \\
\text { Show diverse storytellers as a way to lower medical mistrust by allowing patients to hear from others who look } \\
\text { like them and normalize the decision-making process }\end{array}$ \\
\hline $\begin{array}{l}\text { Difficulty reaching family, friends, or } \\
\text { potential living donors to learn about } \\
\text { transplant and LDKT }\end{array}$ & $\begin{array}{l}\text { Help patients record their own video about their need for a living donor and share it with their social network } \\
\text { on Facebook } \\
\text { Deliver storytelling videos to patients and support network through email, post video links on the center } \\
\text { website, and through iPads with videos loaded for patients to review while undergoing treatment }\end{array}$ \\
\hline
\end{tabular}

LKDT, living kidney donor transplant.

center websites and social media, patient portals, or apps. This allows for repeated education that is staged to readiness, easily delivered regularly by busy providers without additional burden. Patients can learn at a self-guided pace, digging into topics that interest them anytime.

\section{Recommendation 3: Naturally Overcome Health}

Literacy and Sociocultural Barriers by Leveraging the

Diversity of Storytellers

Video stories provide culturally sensitive, health literate education by coming directly from diverse participants who speak using natural, plain language and without medical jargon. Videos for patients with specific values (e.g., spiritual faith) can be created to show how members of this community aligned their values with transplant or overcame cultural and logistical barriers. For example, a short video of Latinx recipients talking about how they came around to the idea of accepting a kidney from a relative can be a powerful tool to address important Latinx cultural significance of protecting family.

Digital Storytelling about Living Donor Transplant
Recommendation 4: Use Resources with Memorable Emotional Valence to Motivate Patients and Living Donors to Consider LDKT

Pairing didactic education with edutainment or firstperson video stories that are emotionally moving and that highlight change talk - where the storyteller explains how they overcame emotional and logistical challenges to LDKT - can help patients overcome barriers and fears by serving as a roadmap and gentle introduction to a potentially scary topic. To overcome barriers associated with the limited readiness of new dialysis patients to learn about transplant, use short, heartwarming videos as a way slowly introduce the topic to overwhelmed patients without adding significant cognitive load.

\section{Recommendation 5: Use Easy-to-Deliver Themed}

Videos to Better Reach and Educate Patients and

Their Social Networks about Transplant and Help

Them Find Living Donors

Lack of a living donor, and fear of approaching loved ones about LDKT, is a key barrier to waitlisting and transplant. 
Providing patients with (1) heartwarming introductory videos that can be shared with family to help them learn about LDKT and (2) videos where storytellers talk about how they broached the topic of LDKT with family and friends supports patients in better leveraging their support networks. Because most patients attend dialysis alone, short videos are an ideal way to give patients education that they can share and can help them to start the conversation about LDKT. In addition, through the Explore Living Donation Storytelling Project, dialysis patients can record a video about their need for a living donor and then share it on social media. Finally, for centers that do not have a mentor program - or those that have suspended it due to COVID-19 - using video stories allows patients to still hear from real donors/recipients.

\section{Conclusion}

Access to print education about transplant with follow-up discussion by providers is quickly becoming outdated and ineffective in this fast-paced world of new, innovative educational technologies. Digital storytelling about transplant can help bridge the gap without adding burden to either patients or providers and can be done affordably using low-cost technology that most patients already carry with them in their pocket at all times.

\section{Acknowledgements}

The authors thank Erica Ho for her contributions to literature searches that helped to inform sections of this article. They also thank Lizeth Ambriz, Catina O'Leary, and Christina Goalby for their professional insights on ways to use video stories at the dialysis center. The authors acknowledge and thank the $>150$ living do- nors, kidney recipients, those in need of a kidney, and their friends and family who have shared a video story as part of the Explore Living Donation Storytelling Project at www.explorelivingdonation.org. These stories help to educate future patients and living donors and raise awareness about the need for more living donors.

\section{Statement of Ethics}

This is a literature review article that did not involve any human research subjects.

\section{Conflict of Interest Statement}

Dr. Amy D. Waterman is the owner and creator of the Explore Living Donation Storytelling Project, which is freely available for the public at www.explorelivingdonation.org. None of the authors have any financial or ethical conflicts of interest to disclose.

\section{Funding Sources}

This was a literature review article that was not supported by any grant or charitable funding. This article does describe the Explore Living Donation Storytelling Project, which was funded in part by a grant from the Terasaki Family Foundation.

\section{Author Contributions}

E.H.W. conducted literature searches, drafted manuscript content, and revised drafts. A.D.W. contributed to manuscript content, reviewed and edited outlines and drafts, and suggested specific literature to include in the review. R.P. contributed to manuscript content, including the specific value of storytelling for health education, and reviewed and edited outlines and drafts. All authors contributed to the framing and direction of the manuscript.

\section{References}

1 Services CfMM. ESRD Quality Incentive Program. Available from: https://www.cms.gov/ Medicare/Quality-Initiatives-Patient-Assessment-Instruments/ESRDQIP. Published 2020.

2 Weiner D, Watnick S. The ESRD quality incentive program-can we bridge the chasm? J Am Soc Nephrol. 2017;28(6):1697-706.

3 Pearson J, Turenne M, Leichtman A. The executive order on kidney care: an opportunity to improve outcomes for individuals with kidney disease. Kidney Int Rep. 2019;4(11): 1519-22.

4 United States Renal Data System. 2018 USRDS annual data report: epidemiology of kidney disease in the United States. Bethesda, MD: National Institutes of Health, National
Institute of Diabetes and Digestive and Kidney Diseases; 2018.

5 United States Renal Data System. 2019 USRDS annual data report: epidemiology of kidney disease in the United States. Bethesda, MD: National Institutes of Health, National Institute of Diabetes and Digestive and Kidney Diseases; 2019.

6 McSorley A-MM, Peipert JD, Gonzalez C, Norris KC, Goalby CJ, Peace LJ, et al. Dialysis providers' perceptions of barriers to transplant for black and low-income patients: a mixed methods analysis guided by the socioecological model for transplant. World Med Health Policy. 2017;9(4):399-416.

7 Waterman AD, Goalby C, Hyland SS, McCabe M, Dinkel KM. Transplant education practices and attitudes in dialysis centers: di- alysis leadership weighs In. J Nephrol Ther. 2012;S4(007).

8 Balhara KS, Kucirka LM, Jaar BG, Segev DL. Disparities in provision of transplant education by profit status of the dialysis center. Am J Transplant. 2012;12(11):3104-10.

9 Fraser SD, Roderick PJ, Casey M, Taal MW, Yuen HM, Nutbeam D. Prevalence and associations of limited health literacy in chronic kidney disease: a systematic review. Nephrol Dial Transplant. 2013;28(1):129-37.

10 Hamoda RE, Gander JC, McPherson LJ, Arriola KJ, Cobb L, Pastan SO, et al. Process evaluation of the RaDIANT community study: a dialysis facility-level intervention to increase referral for kidney transplantation. BMC Nephrol. 2018;19(1):13. 
11 Dageforde LA, Petersen AW, Feurer ID, Cavanaugh KL, Harms KA, Ehrenfeld JM, et al. Health literacy of living kidney donors and kidney transplant recipients. Transplantation. 2014;98(1):88-93.

12 Wachterman MW, McCarthy EP, Marcantonio ER, Ersek M. Mistrust, misperceptions, and miscommunication: a qualitative study of preferences about kidney transplantation among African Americans. Transplant Proc. 2015;47(2):240-6.

13 Hamoda RE, McPherson LJ, Lipford K, Jacob Arriola K, Plantinga L, Gander JC, et al. Association of sociocultural factors with initiation of the kidney transplant evaluation process. Am J Transplant. 2020;20(1):190-203.

14 Sheu J, Ephraim PL, Powe NR, Rabb H, Senga $\mathrm{M}$, Evans KE, et al. African American and non-African American patients' and families' decision making about renal replacement therapies. Qual Health Res. 2012;22(7):9971006.

15 Lipsey AF, Waterman AD, Wood EH, Balliet W. Evaluation of first-person storytelling on changing health-related attitudes, knowledge, behaviors, and outcomes: a scoping review. $\mathrm{Pa}$ tient Educ Couns. 2020 Oct;103(10):1922-34.

16 Garg PP, Frick KD, Diener-West M, Powe NR. Effect of the ownership of dialysis facilities on patients' survival and referral for transplantation. N Engl J Med. 1999;341(22): 1653-60.

17 Lewis L, Dolph B, Said M, Feeley TH, Kayler LK. Enabling conversations: African American patients' changing perceptions of kidney transplantation. J Racial Ethn Health Disparities. 2019;6(3):536-45.
18 Gordon EJ, Lee J, Kang RH, Caicedo JC, Holl JL, Ladner DP, et al. A complex culturally targeted intervention to reduce Hispanic disparities in living kidney donor transplantation: an effectiveness-implementation hybrid study protocol. BMC Health Serv Res. 2018;18(1):368.

19 Waterman $\mathrm{AD}$, Robbins ML, Paiva $\mathrm{AL}$, Peipert JD, Davis LA, Hyland SS, et al. Measuring kidney patients' motivation to pursue living donor kidney transplant: development of stage of change, decisional balance and selfefficacy measures. J Health Psychol. 2015; 20(2):210-21.

20 Rodrigue JR, Paek MJ, Egbuna O, Waterman $\mathrm{AD}$, Schold JD, Pavlakis M, et al. Making house calls increases living donor inquiries and evaluations for blacks on the kidney transplant waiting list. Transplantation. 2014; 98(9):979-86

21 Patzer RE, McPherson L, Redmond N, DuBay D, Zayas C, Hartmann E, et al. A culturally sensitive web-based intervention to improve living donor kidney transplant among African Americans. Kidney Int Rep. 2019;4(9): 1285-95.

22 Gordon EJ, Reddy E, Gil S, Feinglass J, Rodde J, Abecassis MM, et al. Culturally competent transplant program improves Hispanics' knowledge and attitudes about live kidney donation and transplant. Prog Transplant. 2014; 24(1):56-68.

23 Waterman AD, Peipert JD, Xiao H, Goalby CJ, Kawakita S, Lentine KL. Education strategies in dialysis centers associated with increased transplant wait-listing rates. Clin J Am Soc Nephrol. 2020 Feb;104(2):335-42.
24 Lockwood MB, Bidwell JT, Werner DA, Lee CS. Non-biological barriers to referral and the pre-kidney transplant evaluation among African Americans in the United States: a systematic review. Nephrol Nurs J. 2016;43(3):22538 ;

25 Oliver M, Woywodt A, Ahmed A, Saif I. Organ donation, transplantation and religion. Nephrol Dial Transplant. 2011;26(2):437-4.

26 Li MT, Hillyer GC, Husain SA, Mohan S. Cultural barriers to organ donation among Chinese and Korean individuals in the United States: a systematic review. Transpl Int. 2019; 32(10):1001-18.

27 Walker RC, Abel S, Reynolds A, Palmer SC, Walker C, Tipene-Leach DC. Experiences, perspectives and values of Indigenous peoples regarding kidney transplantation: systematic review and thematic synthesis of qualitative studies. Int J Equity Health. 2019;18(1):204.

28 Davis LA, Grogan TM, Cox J, Weng FL. Interand intrapersonal barriers to living donor kidney transplant among black recipients and donors. J Racial Ethn Health Disparities. 2017;4(4):671-9.

29 Waterman AD, Stanley SL, Covelli T, Hazel E, Hong BA, Brennan DC. Living donation decision making: recipients' concerns and educational needs. Prog Transplant. 2006;16(1): 17-23.

30 Waterman $\mathrm{AD}$, Wood $\mathrm{EH}$, Ranasinghe $\mathrm{ON}$, Faye Lipsey A, Anderson C, Balliet W, et al. A digital library for increasing awareness about living donor kidney transplant: a formative study. JMIR Form Res. 2020 Jul 21;4(7): e17441. 